\title{
Identification of vertebral fractures: a moderately severe solution?
}

\author{
E. V. McCloskey ${ }^{1,2,3}$
}

Received: 22 March 2017 / Accepted: 4 April 2017 / Published online: 27 April 2017

(C) International Osteoporosis Foundation and National Osteoporosis Foundation 2017

Vertebral fractures, arguably the most common osteoporotic fracture, have long featured at the heart of the diagnosis and treatment of osteoporosis, with many authorities recommending the presence of a spine fracture as an eligibility criterion for intervention or reimbursement [1-3]. The visual and quantitative methods involved in their characterization have achieved much attention over the last 25 years [4-8]. Despite this, and in the face of initiatives by organizations such as the International Osteoporosis Foundation to improve their detection and reporting [9], they frequently remain undiagnosed, with only about one third or even less coming to clinical attention [10]. However, both radiographically detected (incorrectly termed asymptomatic fractures) and clinical vertebral fractures are associated with significant future fracture risk [11], morbidity [12-14] and mortality [15, 16]. Vertebral fracture assessment (VFA), using lateral spine images acquired with a bone densitometer, is increasingly being advocated for clinical use. It has the advantage of being performed alongside DXA measurement of BMD, thus offering greater convenience for the patient and a substantially lower radiation dose than lateral radiographs [17]. VFA classification of vertebra as normal or fractured shows good concordance with lateral radiograph diagnosis [18-22]. This technique therefore facilitates improved detection of vertebral

E. V. McCloskey

e.v.mccloskey@sheffield.ac.uk

1 Mellanby Centre for Bone Research, University of Sheffield, Sheffield, UK

2 Centre for Integrated research in Musculoskeletal Ageing (CIMA), Mellanby Centre for Bone Research, University of Sheffield, Sheffield, UK

3 Metabolic Bone Centre, Northern General Hospital, S5 7AU, Sheffield, UK fracture. A recent article by Cosman and colleagues in Osteoporosis International reminds us of some important issues that are at least partially independent of the imaging technique used.

Self-reporting of vertebral fractures is unreliable, in contrast to self-recall of previous hip and forearm fractures [23]. As reported by Cosman and colleagues [24], the majority (80\%) of participants in NHANES reporting a previous vertebral fracture was subsequently found to have no fractures on VFA, with the caveat that the upper reaches of the thoracic spine were poorly visualised by VFA. Furthermore, of those with a fracture on VFA, only $8 \%$ had a self-reported vertebral fracture. Interestingly, in a study of women aged 75 years and over in the UK, using a similarly stringent definition of fracture and VFA imaging, we found a prevalence of $14.5 \%$, not dissimilar to that reported by Cosman and colleagues in the USA. In the UK study, only $1.1 \%$ of the UK women had a self-reported vertebral fracture, and over half $(58 \%)$ of these had a fracture confirmed on VFA. In contrast, the prevalence of vertebral fracture in those reporting no history of vertebral fracture was $14 \%$; i.e., the yield in terms of total fractures is greatest when the whole population is imaged, at least at older ages.

Algorithms to target imaging of the spine to individuals deemed to have characteristics associated with their presence have been proposed [25, 26]. For example, height loss, history of back pain, low BMD, past non-vertebral fracture and older age have been identified in various studies. The association of height loss and back pain is greater in those with underlying multiple vertebral fractures, but they perform poorly in identifying individuals with a single vertebral fracture. While the application of criteria such as that from NOF and ISCD does identify a fracture-enriched population, as seen in the study by Cosman and colleagues, sensitivity remains relatively low, particularly in relatively young population samples as seen 
in NHANES (mean age 65 years). Indeed, some have proposed the use of VFA in older age groups regardless of the presence of specific vertebral fracture predictive factors [27], and this can certainly be actioned in clinical referral populations as opposed to population screening [28]. To my knowledge, only one randomised controlled study of screening for vertebral fractures has been published to date, with encouraging results, and more studies are needed [29].

Finally, and perhaps the most important reminder provided by Cosman et al.'s study relates to the classification of the severity or grade of the prevalent vertebral fracture. The technique used in the Cosman study [24], and probably one of the most widely used in epidemiological studies and clinical trials, is the semi-quantitative method of Genant [4]. As stated in the paper, this method examines the vertebrae not just for height loss but additional features including end-plate deformity and buckling of cortices to discriminate from non-fracture vertebral deformities. Such subtleties may be difficult to detect on VFA imaging and, indeed, even on traditional radiographs, and this is particularly true in the setting of grade 1 or mild vertebral fractures. In expert hands such fractures can be identified, but even when images are evaluated by those trained in the technique, there is a significant false positive rate largely due to confusion with non-fracture deformities such as short vertebral height $[30,31]$. Indeed, this was observed in the Cosman study, where one third of those identified as having a fracture were subsequently reclassified as non-fractured; importantly, these mis-called events were reported to be mostly mild wedge deformities [24]. There is good evidence that such fractures are not always associated with low BMD or future non-vertebral fracture risk, unlike moderate (grade 2) or severe (grade 3) vertebral fractures [30, 32]. Further evidence suggests that short vertebral height, a common reason for nonexpert definition of mild vertebral fractures, shows little relationship with age [33]. Interestingly, even in the study by Cosman and colleagues [24], the prevalence of such fractures only increased from $1.7 \%$ in women aged 40-64 years to $4.2 \%$ in those aged over 80 years, with overlapping confidence intervals. This 2.5 -fold increase contrasts with the 12.4-fold increase in moderate or severe vertebral fractures over the same age intervals. Importantly, these mild fractures comprised $61 \%$ of the total vertebral fractures at the younger ages in women. That these mild or grade 1 vertebral fractures are frequently contaminated by non-fracture deformities is even more likely in daily clinical practice of clinicians or general radiologists and may lead to significant overinvestigation and unnecessary treatment. The latter is contrasted with the known under-diagnosis and treatment of patients with existing moderate and severe vertebral fractures [34]. Near-term future strategies should probably focus on identifying those men and women with un-diagnosed moderate or severe vertebral fractures; such approaches might lend themselves more easily to automated or semi-automated detection of vertebral fractures on VFA, radiographs and other imaging modalities, such as CT and MRI.

\section{References}

1. National Osteoporosis Foundation (2015) Clinician's guide to prevention and treatment of osteoporosis. http://nof.org/hcp/resources/ 913. Accessed 9 Feb 2015. p

2. Papaioannou A, Morin S, Cheung AM et al (2010) 2010 clinical practice guidelines for the diagnosis and management of osteoporosis in Canada: summary. CMAJ 182:1864-1873

3. Kanis JA, McCloskey EV, Johansson H, Cooper C, Rizzoli R, Reginster JY (2013) European guidance for the diagnosis and management of osteoporosis in postmenopausal women. Osteoporos Int 24:23-57

4. Genant HK, Wu CY, van Kuijk C, Nevitt MC (1993) Vertebral fracture assessment using a semiquantitative technique. J Bone Miner Res 8:1137-1148

5. McCloskey EV, Spector TD, Eyres KS, Fern ED, O'Rourke N, Vasikaran S, Kanis JA (1993) The assessment of vertebral deformity: a method for use in population studies and clinical trials. Osteoporos Int 3:138-147

6. Eastell R, Cedel SL, Wahner HW, Riggs BL, Melton LJ 3rd (1991) Classification of vertebral fractures. J Bone Miner Res 6:207-215

7. Jiang G, Ferrar L, Barrington NA, Eastell R (2007) Standardised quantitative morphometry: a modified approach for quantitative identification of prevalent vertebral deformities. Osteoporos Int 18:1411-1419

8. Oei L, Rivadeneira F, Felisia L, Breda SJ, Zillikens MC, Hofman A, Uitterlinden A, Krestin GP, Oei EH (2012) Review of radiological scoring methods of osteoporotic vertebral fracturs for clinical and research settings. Eur J Radiol 23:476-486

9. Genant H, Bouxsein M, On behalf of the IOF CSA Bone Imaging Working Group (2011) Vertebral Fracture Initiative. Executive Summary. https://www.iofbonehealth.org/sites/default/files/PDFs/ IOF_VFI-Executive_Summary-English.pdf

10. Cooper C, Atkinson EJ, O'Fallon WM, Melton LJ 3rd (1992) Incidence of clinically diagnosed vertebral fractures: a populationbased study in Rochester, Minnesota, 1985-1989. J Bone Miner Res 7:221-227

11. Klotzbuecher CM, Ross PD, Landsman PB, Abbott TA 3rd, Berger M (2000) Patients with prior fractures have an increased risk of future fractures: a summary of the literature and statistical synthesis. J Bone Miner Res 15:721-739

12. Matthis C, Weber U, O'Neill TW, Raspe H (1998) Health impact associated with vertebral deformities: results from the European Vertebral Osteoporosis Study (EVOS). Osteoporos Int 8:364-372

13. Lips P, Cooper C, Agnusdei D et al (1999) Quality of life in patients with vertebral fractures: validation of the Quality of Life Questionnaire of the European Foundation for Osteoporosis (QUALEFFO). Working Party for Quality of Life of the European Foundation for Osteoporosis. Osteoporos Int 10:150-160

14. Tosteson AN, Gabriel SE, Grove MR, Moncur MM, Kneeland TS, Melton LJ 3rd (2001) Impact of hip and vertebral fractures on quality-adjusted life years. Osteoporos Int 12:1042-1049

15. Kado DM, Browner WS, Palermo L, Nevitt MC, Genant HK, Cummings SR (1999) Vertebral fractures and mortality in older women: a prospective study. Study of osteoporotic fractures research group. Arch Intern Med 159:1215-1220

16. Jalava T, Sarna S, Pylkkanen L et al (2003) Association between vertebral fracture and increased mortality in osteoporotic patients. J Bone Miner Res 18:1254-1260 
17. Genant HK, Li J, Wu CY, Shepherd JA (2000) Vertebral fractures in osteoporosis: a new method for clinical assessment. J Clin Densitom 3:281-290

18. Rea JA, Li J, Blake GM, Steiger P, Genant HK, Fogelman I (2000) Visual assessment of vertebral deformity by X-ray absorptiometry: a highly predictive method to exclude vertebral deformity. Osteoporos Int 11:660-668

19. Schousboe JT, Debold CR (2006) Reliability and accuracy of vertebral fracture assessment with densitometry compared to radiography in clinical practice. Osteoporos Int 17:281-289

20. Chapurlat RD, Duboeuf F, Marion-Audibert HO, Kalpakcioglu B, Mitlak BH, Delmas PD (2006) Effectiveness of instant vertebral assessment to detect prevalent vertebral fracture. Osteoporos Int 17:1189-1195

21. Damiano J, Kolta S, Porcher R, Tournoux C, Dougados M, Roux C (2006) Diagnosis of vertebral fractures by vertebral fracture assessment. J Clin Densitom 9:66-71

22. Lee JH, Lee YK, Oh SH et al (2016) A systematic review of diagnostic accuracy of vertebral fracture assessment (VFA) in postmenopausal women and elderly men. Osteoporos Int 27:1691-1699

23. Ismail AA, O'Neill TW, Cockerill W et al (2000) Validity of selfreport of fractures: results from a prospective study in men and women across Europe. EPOS study Group. European Prospective Osteoporosis Study Group. Osteoporos Int 11:248-254

24. Cosman F, Krege JH, Looker AC, Schousboe JT, Fan B, Sarafrazi Isfahani N, Shepherd JA, Krohn KD, Steiger P, Wilson KE, Genant HK (2017) Spine fracture prevalence in a nationally representative sample of US women and men aged $\geq 40$ years: results from the National Health and Nutrition Examination Survey (NHANES) 2013-2014. Osteoporos Int. doi:10.1007/s00198-017-3948-9

25. International Society for Clinical Densitometry (2015) Official Positions 2015 ISCD Combined
26. Cosman F, de Beur SJ, LeBoff MS, Lewiecki EM, Tanner B, Randall S, Lindsay R (2014) Clinician's guide to prevention and treatment of osteoporosis. Osteoporos Int 25:2359-2381

27. Tobias JH, Hutchinson AP, Hunt LP, McCloskey EV, Stone MD, Martin JC, Thompson PW, Palferman TG, Bhalla AK (2007) Use of clinical risk factors to identify postmenopausal women with vertebral fractures. Osteoporos Int 18:35-43

28. Kuet KP, Charlesworth D, Peel NF (2013) Vertebral fracture assessment scans enhance targeting of investigations and treatment within a fracture risk assessment pathway. Osteoporos Int 24:1007-1014

29. Clark EM, Gould V, Morrison L, Ades AE, Dieppe P, Tobias JH (2012) Randomized controlled trial of a primary care-based screening program to identify older women with prevalent osteoporotic vertebral fractures: Cohort for Skeletal Health in Bristol and Avon (COSHIBA). J Bone Miner Res 27:664-671

30. Ferrar L, Jiang G, Armbrecht G, Reid DM, Roux C, Gluer CC, Felsenberg D, Eastell R (2007) Is short vertebral height always an osteoporotic fracture? The Osteoporosis and Ultrasound Study (OPUS). Bone 41:5-12

31. Ferrar L, Jiang G, Cawthon PM et al (2007) Identification of vertebral fracture and non-osteoporotic short vertebral height in men: the MrOS study. J Bone Miner Res 22:1434-1441

32. Johansson H, Oden A, McCloskey EV, Kanis JA (2014) Mild morphometric vertebral fractures predict vertebral fractures but not nonvertebral fractures. Osteoporos Int 25:235-241

33. Ferrar L, Roux C, Reid DM, Felsenberg D, Gluer CC, Eastell R (2012) Prevalence of non-fracture short vertebral height is similar in premenopausal and postmenopausal women: the osteoporosis and ultrasound study. Osteoporos Int 23:1035-1040

34. Delmas PD, van de Langerijt L, Watts NB, Eastell R, Genant H, Grauer A, Cahall DL (2005) Underdiagnosis of vertebral fractures is a worldwide problem: the IMPACT study. J Bone Miner Res 20: $557-563$ 